\title{
A SEROLOGICAL TEST FOR TUBERCULOSIS
}

\author{
D GOODE, MSc, FIMLS, MIBiol
}

Royal Army Medical College, Millbank

\begin{abstract}
SUMMARY: This paper describes an evaluation of the whole cell agglutination test for tuberculosis ${ }^{\mathfrak{}}$, carried out as Army Medical Directorate Research (AMDR) project 221. A total of eighty-three cases, where the consultants were able to give a final diagnosis, are considered. The test was found to give inaccurate results in 39 per cent of cases under clinical investigation, also to show an 18 per cent false positive result in ante-natal patients who were established as not suffering from tuberculous disease. Apart from the erratic and unreliable results obtained with sera from women patients generally, the results presented here show that the test is too inaccurate to be of clinical value in early disease.
\end{abstract}

\section{Introduction}

Over the past thirty years many serological tests have been proposed to assist the clinician in the diagnosis of early tuberculous disease. Some employed sensitized carrier particles such as the haemagglutination method of Middlebrook and Dubos $^{2}$, latex agglutination was proposed by Dubocyzy and White ${ }^{3}$, whilst others have attempted early diagnosis by fluorescent antibody techniques ${ }^{4}$, or by double gel diffusion ${ }^{5}$.

The difficulties with all of these previous approaches has been that, apart from giving both false negative and false positive results, none have been of real value at the early stages of disease, when clinical and radiological findings were not yet definitive and cultural studies were still awaited. The claim of Nicholls, that a whole cell agglutination method using phenol killed Mycobacterium tuberculosis suspensions of the avirulent strain H.37Ra showed promise for the early confirmation of diagnosis, seemed worthy of investigation and was approved for study as AMDR project 221.

\section{Materials and methods}

Throughout the work paired sera have been examined, the first specimen being obtained by the clinician on the patient's initial presentation, a second specimen being taken at least 14 days after.

Six week cultures of H.37Ra on Löwenstein-Jensen medium were used in the initial trials, the growth being washed off into saline and treated with two per cent phenol for three days before washing with saline and treating with normal sodium hydroxide at $80^{\circ} \mathrm{C}$, as per Nicholls' original paper. The suspension after washing was suspended to an appropriate density in 0.3 per cent sterile saline. Serum obtained from a known case of advanced pulmonary tuberculosis (PTB) who had been under treatment for some months, was used as a control serum in a conventional 'checker-board' type titration to determine the optimal reactive concentration for the antigen.

All tests were carried out in 'Microtitre' round bottomed plastic trays, dilu- 
tions of patients' sera being made in 0.3 per cent saline ranging from one in thinty by nine doubling steps. Incubation was carried out with replicate tests at both $25^{\circ} \mathrm{C}$ and $37^{\circ} \mathrm{C}$, for 24 and 48 hours before reading. As incubation at $37^{\circ} \mathrm{C}$ appeared to make no difference to the ultimate readings when compared with those at lower temperature, all tests after the first 25 sera were carried out at $25^{\circ} \mathrm{C}$. Following the suggestion of Dr Nicholls, the suspension towards the end of 1977 was changed to the virulent H.37Rv strain of Mycobacterium tuberculosis, and I am grateful to Dr R J C Harris, Director MRE, Porton for the provision of a bulk suspension of this strain to prepare the new antigen. This was made in an identical manner to the H.37Ra antigen. Some difficulty was experienced initially in producing suitable preparations in the case of both strains used; the temperature and time of heating appeared critical for maximum sensitivity of the final antigens. All tests presented here were carried out using the virulent H.37v suspension.

\section{Results}

The findings presented here are those obtained from the examination of paired sera received in 1978 from 83 cases of initially suspected tuberculous disease, where the consultants gave a final proven diagnosis for each patient. Definitive evidence was provided where the final diagnosis was other than tuberculous disease. The results are presented as Table I where one titre only is shown for each specimen, this being the highest titre obtained from the examination of paired sera. The level of significance used in the table for serological diagnosis is a titre of one in 120 or higher.

From a study of Table $I$ it will be seen that the serological test gave incorrect results in a positive finding of tuberculous disease for 20 patients as shown by column 1, and incorrect findings of serological negatives for four patients later confirmed by other methods as being tuberculous (column 2). Correct results were obtained in serologically negative tests for 23 cases and a further 24 cases were correct in a finding of tuberculous disease later clinically confirmed (columns 3 and 6). The 12 cases which were old treated and cured PTB showed in nine cases (75 per cent) 'positive' serology, none of these were found to be suffering from tuberculous disease relapse in the final diagnosis.

\section{Other serological tests}

To investigate reasons for non-specific response, all sera showing a titre of one in 120 or higher were tested for rheumatoid factors by the 'Rheumafac test', and all were negative. All sera with titres as above were also tested for syphilis antibodies by the Venereal Disease Research Laboratory test (VDRL Rapid Slide Test Modification), as sera from tuberculous patients not infrequently are known to give a false positive reagin test; again all were negative.

It has been suggested by Nicholls ${ }^{6}$ 'That the majority of false positive results occurred in patients with elevated IgM levels'. Accordingly the sera examined in this report were retested after treatment with 0.02 molar concentration of 2-mercapto-ethanol. No separate table of results is given here, because it was found that although this treatment dropped titres by usually one dilution (sometimes two in 
Table I

Serological findings on 83 patients

\begin{tabular}{|c|c|c|c|c|c|}
\hline \multicolumn{6}{|c|}{ Final Diagnosis in All Columns } \\
\hline $\begin{array}{l}\text { Conditions } \\
\text { other than } \mathrm{TB}\end{array}$ & TB & Not $\mathrm{TB}$ & $\begin{array}{l}\text { Not TB but } \\
\text { old TB cases }\end{array}$ & $\begin{array}{l}\text { Not TB but } \\
\text { old TB cases }\end{array}$ & TB \\
\hline Serology $=\mathrm{TB}$ & $\begin{array}{c}\text { Serology }= \\
\text { Not TB }\end{array}$ & $\begin{array}{c}\text { Serology }= \\
\text { Not TB }\end{array}$ & Serology $=\mathrm{TB}$ & $\begin{array}{c}\text { Serology }= \\
\text { Not TB }\end{array}$ & Serology $=\mathbf{T B}$ \\
\hline $\begin{array}{r}109-960 \\
118-120 \\
150-120 \\
79-120 \\
134-120 \\
100-240 \\
115-480 \\
120-120 \\
81-240 \\
88-480 \\
84-240 \\
132-480 \\
111-240 \\
80-960 \\
70-480 \\
165-120 \\
119-120 \\
105-120 \\
110-120 \\
37-120\end{array}$ & $\begin{array}{l}154-60 \\
103-60 \\
138-60 \\
139-60\end{array}$ & $\begin{array}{r}128-60 \\
142-60 \\
148-30 \\
168-30 \\
124-60 \\
76-60 \\
153-60 \\
161-30 \\
114-60 \\
167-30 \\
72-30 \\
151-60 \\
127-60 \\
102-30 \\
87-60 \\
91-60 \\
164-30 \\
122-60 \\
112-30 \\
96-60 \\
113-30 \\
66-60 \\
141-60\end{array}$ & $\begin{array}{r}133-480 \\
121-480 \\
95-480 \\
104-120 \\
85-120 \\
136-240 \\
145-480 \\
143-240 \\
123-240\end{array}$ & $\begin{array}{r}67-60 \\
108-30 \\
106-30\end{array}$ & $\begin{array}{r}82-480 \\
152-480 \\
140-960 \\
166-120 \\
98-240 \\
156-120 \\
68-960 \\
90-240 \\
116-480 \\
86-480 \\
89-480 \\
69-480 \\
120-120 \\
73-480 \\
71-240 \\
74-240 \\
101-240 \\
92-120 \\
135-120 \\
126-120 \\
131-120 \\
64-120 \\
75-480 \\
63-120\end{array}$ \\
\hline Totals-20 & 4 & 23 & 9 & 3 & $24=83$ \\
\hline
\end{tabular}

In each column the figure on the left is the project reference number for the patient, whilst the figure on the right represents the highest titre obtained from examining two specimens of serum.

high titre sera), in no case did this alter the final conclusion to a result different from the original test.

\section{Examinations of sera from women patients}

In the present work very few sera (10) were from women patients. In previous studies with the avirulent suspension H.37Ra, it was found that women patients very frequently gave titres at or above the significance level of a titre of one in 120 . In a personal communication Dr Nicholls agreed that this had been his experience also and that he felt the significance level of the test needed to be higher in women of fertile age. Following this observation a small series of 50 freshly taken sera sent to the Royal Army Medical College for routine ante-natal serology in 1977, were examined also for TB antibodies by the whole cell agglutination test, using the original H.37Ra (avirulent strain) suspension. Nine of the sera (18 per cent) gave titres of one in 120 or higher. The tests were repeated using the H.37Rv (virulent) strain suspension used in the present work with the same findings, but in most cases a slightly higher (one tube) titre. All of the patients concerned were free from any current suspicion, or past history of tuberculous disease. 


\section{Discussion}

It is considered by the writer that any serological test which is to be of clinical value should fulfil the following criteria:-

To become positive early in clinical disease, not to be limited by age or sex and to have efficiency of presumptive diagnosis of 85 to 90 per cent, whilst returning to normal levels reasonably soon after clinical cure. If the efficiency of the serological whole cell agglutination test for tuberculous infection is considered from the figures presented in Table $I$ it is seen that an incorrect result was obtained in 33 of 83 cases, or 39.7 per cent (columns 1,2 and 4).

Where sera from women were examined titres were frequently above the base line set for significance and in ante-natal patients 18 per cent gave 'false positive' serological findings using the whole cell agglutination test. It could be argued that the suspension prepared was too sensitive and that with reduced sensitivity these 'biological false positives' may be reduced. This is obviously so, however, if a less sensitive suspension had been used in the present series of examinations a total of eight correct serological findings would have been removed from column 6 in Table I reducing the pencentage of correct findings from 29 to 19 per cent. If on the other hand the level of significance is raised to a titre of one in 240 instead of one in 120 , then ten false positive findings are removed from column 1 , but equally the eight correct findings are removed from column 6 again.

In summary it can be said that the test does not on average become positive to a sufficiently high degree in early disease to differentiate reliably between infections and other non specific responses; that it is rather unreliable in women patients and especially so in ante-natal patients; whilst at best in the present series of 83 patients the test was correct in 47 cases or 56 per cent. Finally once 'positive' the patients serum would appear to retain a high titre for some years, thus making the test of no value in screening for relapses, an area in which of course it was hoped to be informative to the clinician.

\section{Acknowledgements}

This research project is now terminated and $I$ thank all clinicians and pathologists whose co-operation made the evaluation possible. I am especially gratefuI to the Chest Unit and Leishman Laboratory at the Cambridge Military Hospital, Aldershot from whom a large number of specimens were received throughout the trials with both avirulent and virulent suspensions.

\section{REFERENCES}

1. Nicholls, A C (1975). A serodiagnostic test for tuberculosis. Journal of Clinical Pathology 28, 850-853.

2. Middlebrook, G and Dubos R J (1948). Specific serum agglutination of erythrocytes sensitized with extracts of tubercle bacilli. Journal of Experimental Medicine 88, 521-528.

3. Duboczy, $B O$ and WhITE, F C (1969). Further studies with the direct latex agglutination test in tuberculosis. American Review of Respiratory Diseases 100, 364-371.

4. NAssau, E and Merrick, A J (1970). The fluorescent antibody test in human tuberculosis; a pilot study. Tubercle (Edinburgh) 51, 430-436.

5. Partlett, R C and Youmans, G P (1959). An evaluation of the specificity and sensitivity of a gel double-diffusion test for tuberculosis; a double blind study. American Review of Respiratory Diseases 80, 153-166.

6. Nicholls, A C (1977). Serological test for tuberculosis. British Medical Journal 2, 46-47. 